specialists. Its practical and common-sense approach makes it of interest and considerable value to general practitioners and although rather advanced for senior students, many would find it a stimulating and refreshing contrast to some standard textbooks.

\section{A TEXTBOOK OF CLINICAL NEUROLOGY}

By J. M. Nielsen, B.S., M.D., F.A.C.P. 3rd Edition. Pp. xiv +709 , with 212 illustrations. London: Cassell \& Co. 1951. £3 r5s. od.

This is a most readable book, practical, honest, clear, printed beautifully and well illustrated.

It has the great virtue of not being in the least alarming - a rare quality in textbooks of neurology.

It is not, however, a book of reference. Only larger and (in all senses) heavier books can serve this purpose. But it is an excellent book for anyone wishing to be introduced to a neurological subject or disease. Moreover it is really up to date - so much so that examinees would be well advised not to quote some of the treatments advised (such as intravenous procaine for cerebral thrombosis) which may be of great value but are as yet probably untried and certainly unaccepted in this country.

The chapters on recent advances (for example those on electroencephalography and angiography) are for the most part sound introductions to their subjects. They make no attempt to be comprehensive and so they avoid the dull, cataloguing atmosphere which makes so many books difficult to read.

A strange exception is the chapter on electromyography, from which it is difficult to get any clear view of the subject. The confusion is worst, oddly enough, in the plates to this chapter. It is almost impossible to follow their subtitles.

There are not a few statements and some classifications which are open to objection. What he calls progressive ophthalmoplegia of nuclear origin has a distribution indicating that it is far more probably a myopathy, and his claims for the use of tocopherol in amyotrophic lateral sclerosis would hardly be accepted here. Such objections, however, are inevitable in any live textbook on a live subject and they are relatively of minor importance.

This is outstandingly the type of book that a busy practitioner would enjoy. It is easy to dip into and quite difficult to put down.

It is certainly costly but the paper is luxurious, the lay-out spacious and the plates plentiful and good.

\section{C.E.}

\section{CARDIOSCOPY}

By William Evans, M.D., D.Sc., F.R.C.P. Pp. $\mathrm{xi}+$ 150, with 207 illustrations. London: Butterworth \& Co. r952. 40s.

It is a salutary experience for a radiologist to review a book written by a physician on a subject which is primarily of a radiological flavour.

To the purist the title 'Cardioscopy' might be criticized as misleading and the use of the terms ' outer border' and 'mesial heart shadow' in a description of the oblique views of the heart could lead to confusion; ' right and left borders as seen by the observer' would have been a happier choice of terminology.

These minor criticisms apart, this is an excellent little book or atlas of a wide range of cardiac conditions likely to be met with on fluoroscopic examination of the heart from displacement of the heart in chest deformities to behaviour of the heart in endocrine disfunctions.

Dr. Evans is to be congratulated on his choice of illustrations which are exceedingly well reproduced and really illustrate the points in the descriptive text, which is written in a straightforward manner and leaves no room for ambiguity, particularly on a subject which is difficult to transcribe from motion as seen to static cold print. On few occasions only does he transgress and confuse the fluorescent and the photographic image.

A medical student's curriculum is so packed one hesitates to load him with more and more reading, particularly of a specialized nature. There is, however, a hard core whose appetite for literature is insatiable, they will read and enjoy this book and the rest will benefit if only to look at the illustrations and read their captions. It is to the postgraduate student in diagnostic radiology and his colleague working for higher examinations in medicine that this book will most appeal. To the former, it forms a basis for the understanding of more elaborate and detailed reading in his radiological studies of the heart and to the latter a fund of practical knowledge which may tip the scales for a gold medal or that final viva voca examination.

T.R.R.

\section{PHYSICAL MEDICINE SERVICES Vol. I}

Muscle Relaxation as an Aid to Psychotherapy By G. Garmany, B.Sc., M.B., Ch.B., M.R.C.P., D.P.M. Pp. 65. London: The Actinic Press, Ltd. 1952. 3s. $6 \mathrm{~d}$.

This monograph explains the application of physical medicine to psychiatric treatment. The training of patients in muscle relaxation is part of the curriculum in the course of training of physiotherapists and the special application of this form of treatment is explained and described. The author rightly stresses the limitations of the treatment and the fact that it is only a part of the treatment which is prescribed by the psychiatrist in carefully selected cases.

It is a most readable and informative book for physiotherapists and medical men. 